\title{
Flux-Weakening Control of Dual Three-Phase PMSM Based on Vector Space Decomposition Control
}

\author{
Yashan $\mathrm{Hu}$, Xuefei Li, and Xiandong Ma
}

\begin{abstract}
This paper proposes a flux-weakening (FW) control for dual three-phase permanent magnet synchronous machine (DT-PMSM) based on vector space decomposition (VSD) control, where the output voltage in $\alpha \beta$ sub-plane is employed for voltage feedback in the flux-weakening control loop. As the fundamental components are mapped to $\alpha \beta$ sub-plane while the 5th and 7th harmonics are projected to harmonic $z_{1} z_{2}$ sub-plane, the flux-weakening current from this new control in $\alpha \beta$ subplane is sixth harmonic-free regardless of the 5th and 7th harmonics being resulted from the non-sinusoidal back EMF or inverter non-linearity. The proposed control is compared with the conventional FW feedback control extended for DT-PMSM, where the FW control is applied to the two sets of three-phase windings separately. The experimental results show that the proposed FW control based on VSD is superior to the conventional FW control in terms of reduction in current unbalance and harmonic currents.
\end{abstract}

Index Terms-Double star PM machine, dual three-phase PM SM, flux-weakening control, six-phase PM machine, vector space decomposition.

\section{NOMENCLATURE}

$\begin{array}{ll}F_{\alpha}, F_{\beta} & \text { Components in the } \alpha \beta \text { sub-plane. } \\ & F \text { can be } R, v, i, \psi_{s} \text { or } \psi_{f}, \text { which represents } \\ & \text { stator resistance, voltage, current, stator flux- } \\ & \text { linkage, or PM flux-linkage } \\ F_{z l}, F_{z 2} & \text { Components in the } z_{1} z_{2} \text { sub-plane. } \\ \boldsymbol{F}_{\alpha \boldsymbol{\beta}} & \text { Vector } F_{\alpha}+j F_{\beta} \\ \boldsymbol{F}_{z 1 z 2} & \text { Vector } F_{z 1}+j F_{z 2} \\ F_{\alpha 1}, F_{\beta 1} & \text { Components of phase-ABC in } \alpha \beta \text {-frame } \\ F_{\alpha 2}, F_{\beta 2} & \text { Components of phase-XYZ in } \alpha \beta \text {-frame } \\ \boldsymbol{F}_{\alpha \beta 1} & \text { Vector } F_{\alpha 1}+j F_{\beta 1} \\ \boldsymbol{F}_{\alpha \beta 2} & \text { Vector } F_{\alpha 2}+j F_{\beta 2} \\ F_{d}, F_{q} & \text { Components in } d q \text {-frame in } \alpha \beta \text { sub-plane for } \\ F_{d z}, F_{q z} & \text { DT-PMSM } \\ F_{d 1}, F_{q 1} & \text { Components in } d q z \text {-frame in } z 1 z 2 \text { sub-plane } \\ F_{d 2}, F_{q 2} & \text { Cor DT-PMSM } \\ v_{m a x}^{*} & \text { Components in the } d q \text {-frame for phase-ABC } \\ v_{m} & \text { Voltage magnitude reference } \\ v_{m 1} & \text { Voltage magnitude feedback in } \alpha \beta \text { sub-plane } \\ v_{m 2} & \text { Voltage magnitude feedback for phase-ABC } \\ \theta_{e} & \text { Voltage magnitude feedback for phase-XYZ } \\ \omega_{e} & \text { Rotor electrical angle } \\ & \text { electrical speed }\end{array}$

\section{INTRODUCTION}

ingle three-phase inverter-fed machine is extensively used

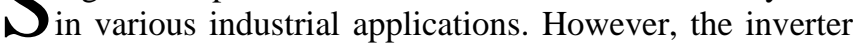
rating can not increase up to a certain level due to the limitation on the power rating of semiconductor devices. Two attractive solutions to this problem are either using multi-level inverter or multi-phase machines. Whether it is better to use multi-phase machines or multi-level converters depends on the application. Insulation level is one of the limiting factors that hinder the use of multi-level inverter. Therefore, multiphase inverter fed machines operating at a lower voltage level are preferred [1].

Compared with the single three-phase counterpart with the same drive current limit, the multi-phase machine offers many advantages such as multiple power capacity, reduced torque pulsation, reduced stator current, lower DC-link current harmonics, higher reliability at the system level, increased power density for the same volume machine, and additional degrees of freedom, and can be driven by multiple single three-phase inverters [2-9]. The dual three-phase permanent magnet synchronous machine (DT-PMSM) has double power capacity and the characteristic of sixth-order torque harmonic pulsation-free. Over the last decades, the DT-PMSM has been widely applied to many industrial applications such as aerospace, electric vehicles, "more-electric" aircraft, and wind turbines [8, 10-13].

The power topology of dual three-phase voltage source inverter (VSI) drive, i.e. dual inverter, can be illustrated in Fig. 1 , which is constructed by two single three-phase H-bridge voltage source inverters (VSIs) with a common DC voltage source [7]. The asymmetrical DT-PMSM has two sets of single three-phase windings, where the first set is named as phase-ABC, whilst the second set is named as phase-XYZ. Both sets of three-phase windings use the data from the same position sensor or estimation. The electrical phase shift angle between phase- $\mathrm{ABC}$ and $-\mathrm{XYZ}$ is $30^{\circ}$, which is determined by the relationship of the measured phase back$\mathrm{EMFs}$, and the neutral points for phase-ABC and $-\mathrm{XYZ}$ are isolated. A dual inverter is used to drive phase-ABC and phase-XYZ. When the DT-PMSM works under regenerative braking mode, the dual inverter works as a boost rectifier and transfers power from DT-PMSM to the DC bus.

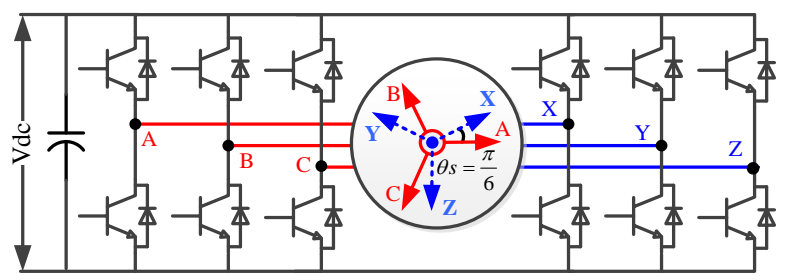

Fig. 1 DT-PMSM drive system.

To extend the power and speed operation range which is constrained by a given DC-link voltage, the FW control is usually adopted to weaken the air-gap flux by utilization of 
the FW current ( $d$-axis current) [14-16]. Based on the conventional decoupling vector control with $d q$-axis current regulation for a single three-phase machine, the strategies of FW control can be classified into feed-forward [17-22] and feedback methods [16, 23-32]. The FW control of the feedforward method has the advantage of excellent dynamic performance; however, the accuracy of FW current from the feed-forward method relies heavily on the accuracy of machine parameters, such as the flux-linkage and inductances, which might vary with loads and temperature [18, 33, 34]. The feedback method is robust against the deviation of machine parameters; however, its dynamic performance is not as good as the feed-forward method. To solve this issue, the feedforward and feedback methods can be combined in a hybrid method $[35,36]$.

The feedback in the FW control of feedback method can be the voltage magnitude error [16, 24-28], the voltage error before and after the pulse width modulation (PWM) module $[31,32]$, or the error between the PWM period and the calculated active time for the synthesis of voltage vector command[37]. The first method is applicable under both linear PWM and over-modulation regions due to alterable voltage reference; however, the latter two methods are specifically designed for the over-modulation region and thus cannot achieve a FW operation in the linear PWM region. Although the FW operation in the over-modulation region can increase the power capability, it also results in increased harmonic voltage, current, and torque ripple, which might not be applicable in some applications demanding small torque ripples such as the MW wind turbine PMSM generator.

In terms of the vector control of DT-PMSM, it can generally be divided into two categories [38]. The first is twoindividual current control, which is based on the double $d q$ synchronous frames $\left(d_{1} q_{1}-d_{2} q_{2}\right.$-frame $)$ model with mutual coupling voltages between two frames, i.e. $d_{1} q_{1}$-frame for the first set of three-phase windings (phase-ABC) and $d_{2} q_{2}$-frame for the second three-phase windings (phase-XYZ) $[6,7,39$, 40]. If neglecting compensation of the mutual coupling between phase-ABC and -XYZ, two commercial single threephase drives can work separately to drive the DT-PMSM with the equal torque command.

The second vector control strategy of DT-PMSM is the VSD control $[3,41]$ with two current regulators in the $\alpha \beta$ subplane and two current regulators in the $z_{1} z_{2}$ sub-plane. The VSD control is prevailing as the DT-PMSM can be treated as a single three-phase machine in the $\alpha \beta$ sub-plane and a resistance inductance $(R L)$ load in the $z_{1} z_{2}$ sub-plane. since there is no mutual coupling between the $\alpha \beta$ sub-plane and $z_{1} z_{2}$ sub-plane [3, 42], therefore it can provide an excellent dynamic torque performance.

Theoretically, the FW control of DT-PMSM can be implemented based on the aforementioned two-individual current control and VSD control. The efficiency of dual inverter drives for the series split symmetrical DT-PMSM considering field weakening region is discussed in [43], where the phase shift angle between two sets of three-phase windings is zero. In [43], the machine is treated as two separate single three-phase machines and two independent drivers with their corresponding FW control are adopted.

The concept of FW control based on direct torque control (DTC) for a DT-PMSM is presented in [44], the DT-PMSM is treated as a six-phase machine based on the VSD theory [3], and the voltage and current in $\alpha \beta$ sub-plane are employed for the flux-linkage feedback. However, the harmonic components in the $z_{1} z_{2}$ sub-plane are not considered. As there might be abundant 5 th and 7 th harmonic voltages resulted from inverter's nonlinearity and machine's non-sinusoidal back-EMF, it will result in abundant 5th and 7th harmonic currents if without current regulation in $z_{1} z_{2}$ sub-plane [41]. Meanwhile, the experimental results are not provided for validation. A FW control based on VSD control is presented in [45], wherer the FW is activated simply by the speed. When the speed is lower than the switching speed, it works under the $i_{d}=0$ control, while when the speed is higher than the switching speed, it switchs to FW control with $d$-axis voltage command output directly without FW current control anymore.

In DT-PMSM, individual $d q$-axis voltages in $d_{1} q_{1^{-}} d_{2} q_{2^{-}}$ frame contain the 6 th harmonic component. The 6 th harmonic component will then propagate through the control loop and affect the harmonic content of the $d$-axis current. This paper proposes a FW control based on VSD vector control to overcome this problem. With this new controller, the fluxweakening current from this new control is the 6th harmonic free regardless of the 5th and 7th harmonics resulted from the non-sinusoidal back EMF and inverter non-linearity. Firstly, the conventional FW feedback control extended for asymmetrical DT-PMSM is studied, where the conventional vector control and FW control for a single three-phase system are applied to phase-ABC and -XYZ separately. The main deficiencies of the FW control based on two-individual current control will be discussed in detail in Section II and then the reduction of current harmonics and unbalance of the proposed control is demonstrated in Section III. Finally, the comparative experiments are made on a prototype DT-PMSM, which validates that the proposed FW control is superior to the conventional FW control.

\section{CONVENTIONAL FLUX-WEAKENING CONTROL FOR DUAL THREE-PHASE PMSM}

The mathematical modeling of DT-PMSM based on the double synchronous $d q$-frames $\left(d_{1} q_{1}-d_{2} q_{2}\right.$-frame) is detailed in [38]. If neglecting the mutual coupling voltages between phase-ABC and -XYZ, the DT-PMSM can be treated as two single three-phase machines with coupling voltages between two sets of three-phase windings. Then the conventional FW control based on the voltage magnitude feedback for single three-phase PMSM [16, 24-28, 46] can be extended for DTPMSM, which is demonstrated in Fig. 2. The FW control is based on the 2-individual current control [7] [38], where two channels of individual vector controller and FW controller are applied to each single three-phase windings. The upper and lower channels in Fig. 2 are for the control of phase-ABC and phase-XYZ respectively. Both channels share the same quadrature current reference $i_{q}^{*}$, which might be from the speed control loop in the constant speed mode or torque control loop in the constant torque mode. The output voltage magnitude $v_{m 1}$ from phase-ABC in the first channel is employed for FW control of phase-ABC, while the output voltage magnitude $v_{m 2}$ from phase- $\mathrm{XYZ}$ is employed for $\mathrm{FW}$ control of phase-XYZ.

The FW current $i_{d 1}^{*}$ for phase-ABC and $i_{d 2}^{*}$ for phase-XYZ are then derived by the proportional-integral (PI) regulators 
with voltage error input. As the magnitude of current vectors is limited by the maximum current $I_{\max }$, the real quadrature current reference $i_{q 1}^{*}$ is the minimum value of $i_{q}^{*}$ and $i_{q 1 \max }^{*}$ if $i_{q}^{*}$ is positive, or the maximum value of $i_{q}^{*}$ and $-i_{q 1 \text { max }}^{*}$ if $i_{q}^{*}$ is negative. This constraint is also applied to $i_{q 2}^{*}$ generation.

For a given DC bus volage $v_{d c}$, the maximum linear output voltage with the space vector PWM (SVPWM) strategy is $v_{d c} / \sqrt{3}$. Since the reserved voltage margin $v_{\Delta}$ accounting for the harmonic voltage is essential, consequently, the maximum output voltage magnitude $v_{m}^{*}$ will be $v_{d c} / \sqrt{3}-v_{\Delta}$ to guarantee the operation in the region of linear PWM modulation.

It is worth noting that there are 5th and 7th harmonic voltages resulted from the non-sinusoidal back-EMF or inverter non-linearity which turn into 6th harmonic voltages in the $d_{1} q_{1}-d_{2} q_{2}$-frame [41]. Assuming the 5th and 7th harmonics in the phase voltage are expressed as

$$
v_{5 \& 7 t h}=v_{5 t h}+v_{7 t h}=\left[\begin{array}{c}
v_{a 5 t h}\left(\theta_{e}-0 \theta_{s}\right) \\
v_{a 5 t h}\left(\theta_{e}-1 \theta_{s}\right) \\
v_{a 5 t h}\left(\theta_{e}-4 \theta_{s}\right) \\
v_{a 5 t h}\left(\theta_{e}-5 \theta_{s}\right) \\
v_{a 5 t h}\left(\theta_{e}-8 \theta_{s}\right) \\
v_{a 5 t h}\left(\theta_{e}-9 \theta_{s}\right)
\end{array}\right]+\left[\begin{array}{c}
v_{a 7 t h}\left(\theta_{e}-0 \theta_{s}\right) \\
v_{a 7 t h}\left(\theta_{e}-1 \theta_{s}\right) \\
v_{a 7 t h}\left(\theta_{e}-4 \theta_{s}\right) \\
v_{a 7 t h}\left(\theta_{e}-5 \theta_{s}\right) \\
v_{a 7 t h}\left(\theta_{e}-8 \theta_{s}\right) \\
v_{a 7 t h}\left(\theta_{e}-9 \theta_{s}\right)
\end{array}\right]
$$

where $\theta_{e}$ is $\mathrm{PM}$ rotor electrical angle; $v_{a 5 t h}\left(\theta_{e}\right)$ and $v_{a 7 t h}\left(\theta_{e}\right)$ are the 5 th and 7 th harmonics in phase-A. They can be expressed by (2) and (3) respectively, where $k_{v 5}$ and $k_{v 7}$ are the corresponding amplitudes while $\theta_{v 5}$ and $\theta_{v 7}$ are the corresponding offset angle.

$$
\begin{aligned}
& v_{a 5 t h}\left(\theta_{e}\right)=k_{v 5} \cos \left(5\left(\theta_{e}+\pi / 2\right)+\theta_{v 5}\right) \\
& v_{a 7 t h}\left(\theta_{e}\right)=k_{v 7} \cos \left(7\left(\theta_{e}+\pi / 2\right)+\theta_{v 7}\right)
\end{aligned}
$$

The 5th and 7th harmonic phase voltages are then converted to the 6th harmonics in the $d_{1} q_{1}-d_{2} q_{2}$-frame, which can be expressed as (4).

$$
\begin{aligned}
& v_{d 2_{-} 6 t h}=-v_{d 1_{-} 6 t h}=k_{v 5} \sin \left(6 \theta_{e}+\theta_{v 5}\right)-k_{v 7} \sin \left(6 \theta_{e}+\theta_{v 7}\right) \\
& v_{q 2_{-} 6 t h}=-v_{q 1_{-} 6 t h}=k_{v 5} \cos \left(6 \theta_{e}+\theta_{v 5}\right)+k_{v 7} \cos \left(6 \theta_{e}+\theta_{v 7}\right)
\end{aligned}
$$

where $v_{d 1 \_6 t h}$ and $v_{q 1 \_6 t h}$ are the 6th harmonic voltages in $d_{1} q_{1}$-frame for phase $\mathrm{ABC}, v_{d 2_{-} 6 t h}$ and $v_{q 2 \_6 t h}$ are 6th harmonic voltages in the $d_{2} q_{2}$-frame for phase XYZ, respectively. Therefore, the $d q$-axis voltages in phase-ABC and $-\mathrm{XYZ}$ when accounting for the fundamental and 6th harmonics can be expressed as (5), and (6).

$$
\begin{array}{r}
\left\{\begin{array}{l}
v_{d 1}=v_{d 0}-\left(k_{v 5} \sin \left(6 \theta_{e}+\theta_{v 5}\right)-k_{v 7} \sin \left(6 \theta_{e}+\theta_{v 7}\right)\right) \\
v_{q 1}=v_{q 0}-\left(k_{v 5} \cos \left(6 \theta_{e}+\theta_{v 5}\right)+k_{v 7} \cos \left(6 \theta_{e}+\theta_{v 7}\right)\right)
\end{array}\right. \\
\left\{\begin{array}{l}
v_{d 2}=v_{d 0}+\left(k_{v 5} \sin \left(6 \theta_{e}+\theta_{v 5}\right)-k_{v 7} \sin \left(6 \theta_{e}+\theta_{v 7}\right)\right) \\
v_{q 2}=v_{q 0}+\left(k_{v 5} \cos \left(6 \theta_{e}+\theta_{v 5}\right)+k_{v 7} \cos \left(6 \theta_{e}+\theta_{v 7}\right)\right)
\end{array}\right.
\end{array}
$$

where $v_{d 0}$ and $v_{q 0}$ are DC components that are from the fundamental component in the phase voltage.

Assuming the output voltage is equal to the voltage reference, i.e., $v_{d 1}^{*}=v_{d 1}, v_{q 1}^{*}=v_{q 1}, v_{d 2}^{*}=v_{d 2}, v_{q 2}^{*}=v_{q 2}$, then the magnitude of output voltages $v_{m 1}$ and $v_{m 2}$ can be expressed as (7).

$$
v_{m 1}=\sqrt{v_{d 1}^{* 2}+v_{q 1}^{* 2}} ; \quad v_{m 2}=\sqrt{v_{d 2}^{* 2}+v_{q 2}^{* 2}}
$$

Substituting (5) and (6) into (7), it will be found that there is the 6th harmonic in the voltage magnitude feedback $v_{m 1}$ and $v_{m 2}$, which will be validated in the experiment part Section-IV(A). The 6th harmonics in $v_{m 1}$ and $v_{m 2}$ will propagate through the FW PI controllers and then result in 6th harmonics in the FW currents.

It is worth noting that the 6th harmonic currents in the $d_{1} q_{1^{-}}$ $d_{2} q_{2}$-frame cannot be suppressed effectively by the conventional PI controller. Therefore, a resonance control [47] with the center frequency of six times of fundament frequency is employed to suppress the 6th harmonic currents in $d_{1} q_{1^{-}}$ $d_{2} q_{2}$-frame [41]. It should also be noted that since the FW currents of phase-ABC and -XYZ are from different FW controllers, they might be different due to the DT-PMSM asymmetry. Although the torque current $i_{q}^{*}$ are the same, e.g., they are both from the speed controller, the $i_{q 1}^{*}$ and $i_{q 2}^{*}$ might be different due to the different FW currents and the constraints of the same current limit. Therefore, the currents of phase-ABC and phase-XYZ might be unbalanced. 


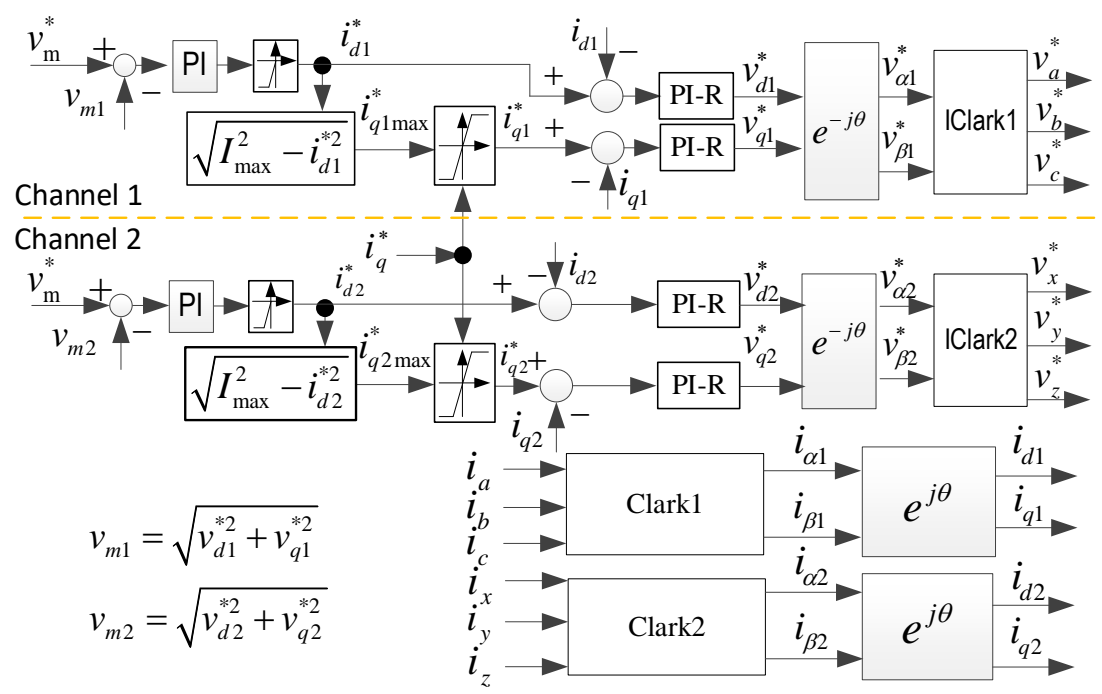

Fig. 2 Conventional FW control extended for DT-PMSM.

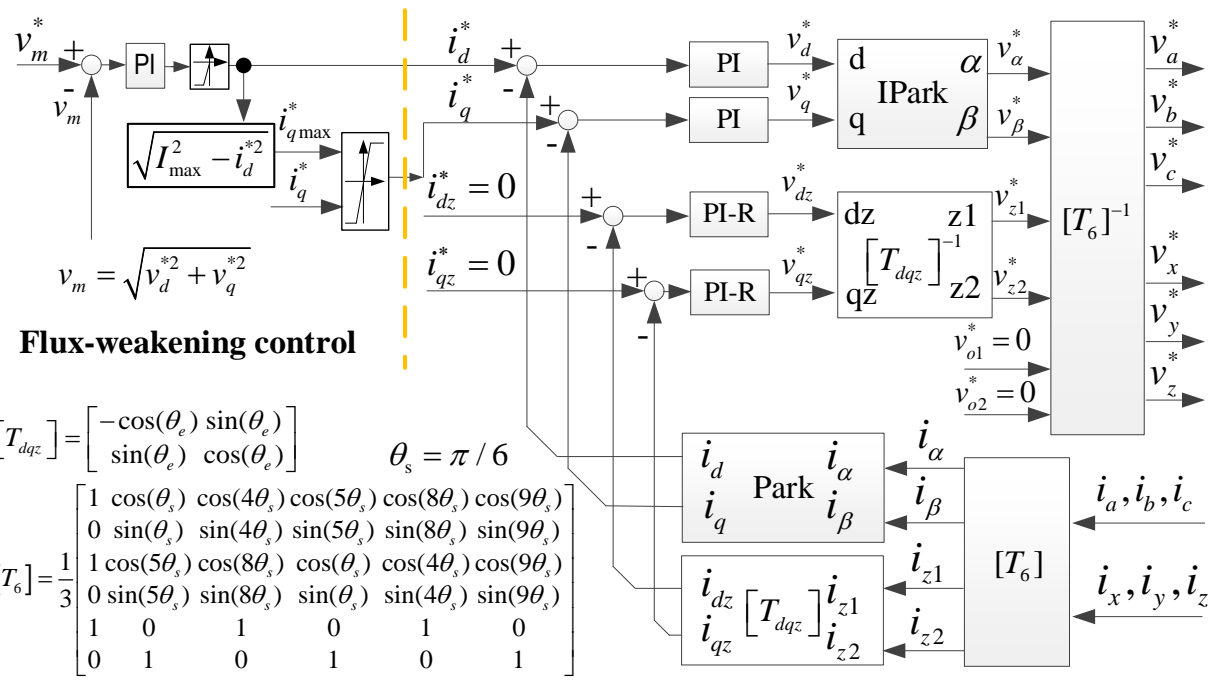

Fig. 3 Proposed FW control based on VSD control.

\section{Proposed FluX-WEAKENING CONTROL BASED ON VECTOR SPACE DECOMPOSITION CONTROL}

According to the VSD theory for the dual three-phase system detailed in $[3,41]$, the six-dimensional cartesian coordinate system in the $a b c-x y z$ frame can be decomposed into three orthogonal sub-spaces, i.e. $\alpha \beta, z_{1} z_{2}, o_{1} o_{2}$ sub-planes. By a dedicated [T6] matrix transformation detailed in [3, 41], different harmonics are projected to different sub-planes, i.e. the fundamental and $(12 \mathrm{k} \pm 1) \mathrm{th}, \mathrm{k}=1,2 \ldots$ harmonics in the $a b c-x y z$ frame are projected to $\alpha \beta$ sub-plane; the $(6 \mathrm{k} \pm 1)$ th, $\mathrm{k}=1,3,5 \ldots$ harmonics in the $a b c-x y z$ frame are projected to $z_{1} z_{2}$ sub-plane; the (3k)th, $\mathrm{k}=0,1,3,5 \ldots$ harmonics in the $a b c$ $x y z$ frame are projected to $o_{1} o_{2}$ sub-plane. Since the 5th and 7 th harmonics are mapped to the $z_{1} z_{2}$ sub-plane rather than the $\alpha \beta$ sub-plane, this feature can be exploited for FW feedback control of DT-PMSM.

In the VSD control of DT-PMSM, the components in the $d q$-frame and $d q z$-frame can be derived by (8) and (9) respectively [41].

$$
\left[\begin{array}{l}
F_{d} \\
F_{q}
\end{array}\right]=\left[T_{\text {park }}\right]\left[\begin{array}{l}
F_{\alpha} \\
F_{\beta}
\end{array}\right]=\left[\begin{array}{cc}
\cos \left(\theta_{e}\right) & \sin \left(\theta_{e}\right) \\
-\sin \left(\theta_{e}\right) & \cos \left(\theta_{e}\right)
\end{array}\right]\left[\begin{array}{c}
F_{\alpha} \\
F_{\beta}
\end{array}\right]
$$

$$
\left[\begin{array}{l}
F_{d z} \\
F_{q z}
\end{array}\right]=\left[T_{d q z}\right]\left[\begin{array}{l}
F_{z 1} \\
F_{z 2}
\end{array}\right]=\left[\begin{array}{cc}
-\cos \left(\theta_{e}\right) & \sin \left(\theta_{e}\right) \\
\sin \left(\theta_{e}\right) & \cos \left(\theta_{e}\right)
\end{array}\right]\left[\begin{array}{l}
F_{z 1} \\
F_{z 2}
\end{array}\right]
$$

The VSD mathematical modeling of DT-PMSM is detailed in [38], where the voltage equations in $d q$-frame and $d q z$-frame can be expressed as (10) and (11) respectively.

$$
\begin{gathered}
{\left[\begin{array}{l}
v_{d} \\
v_{q}
\end{array}\right]=\left[\begin{array}{cc}
R_{s}+L_{d}^{e q u} s & 0 \\
0 & R+L_{q}^{e q u} s
\end{array}\right]\left[\begin{array}{l}
i_{d} \\
i_{q}
\end{array}\right]+\omega\left[\begin{array}{c}
-L_{q}^{e q u} i_{q} \\
L_{d}^{e q u} i_{d}+\psi_{f d}
\end{array}\right]} \\
{\left[\begin{array}{c}
v_{d z} \\
v_{q z}
\end{array}\right]=\left[\begin{array}{cc}
R_{s}+L_{d z} s & 0 \\
0 & R_{s}+L_{q z} s
\end{array}\right]\left[\begin{array}{l}
i_{d z} \\
i_{q z}
\end{array}\right]+\omega\left[\begin{array}{c}
-L_{q z} i_{q z} \\
L_{d z} i_{d z}
\end{array}\right]}
\end{gathered}
$$

where $L_{d}^{e q u}$ and $L_{q}^{e q u}$ are equivalent inductances in $d q$-frame in $\alpha \beta$ sub-plane; $L_{d z}$ and $L_{q z}$ are equivalent inductances in $d q z$-frame in $z_{1} z_{2}$ sub-plane; $\psi_{f d}$ is $d$-axis PM flux-linkage. As can be seen from (10), it has the same voltage equations as the single three-phase PMSM counterpart.

The relationship between $d_{1} q_{1}-d_{2} q_{2}$-frame for double single three-phase system and $d q$-frame, $d q z$-frame based on VSD theory for the six-dimensional machine system can be illustrated in Fig. 4 [38], which can be expressed as

$$
F_{d 2}=F_{d}+F_{d z} ; F_{d 1}=F_{d}-F_{d z}
$$




$$
F_{q 2}=F_{q}+F_{q z} ; F_{q 1}=F_{q}-F_{q z}
$$

By combining (5), (6), (12), and (13), it can be derived that

$$
\left[\begin{array}{l}
v_{d z} \\
v_{q z}
\end{array}\right]=\left[\begin{array}{l}
v_{d 2_{-} 6 t h} \\
v_{q 2_{-} 6 t h}
\end{array}\right]=-\left[\begin{array}{l}
v_{d 1_{-} 6 t h} \\
v_{q 1_{-} 6 t h}
\end{array}\right]
$$

The eq. (14) indicates that the 5th and 7th harmonic voltages are all mapped to the 6th harmonics in the $d q z$-frame. Therefore, the voltages in the $d q$-frame in the $\alpha \beta$ sub-plane are immune to the 6 th harmonics.

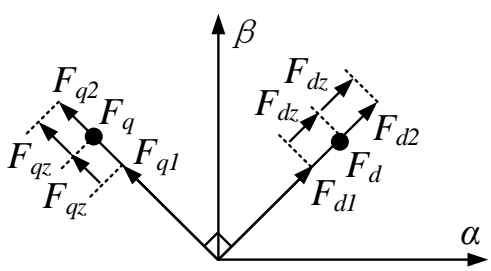

Fig. 4 Relationship between $d_{1} q_{1}$ - $d_{2} q_{2}$-frame and $d q$-frame, $d q z$-frame.

The magnitude of output voltage $v_{m}$ in $d q$-frame in $\alpha \beta$ subplane can be expressed as

$$
v_{m}=\sqrt{v_{d}^{* 2}+v_{q}^{* 2}}
$$

As the fundamental components are projected to the $\alpha \beta$ subplane, the majority of the inverter output voltages are from the fundamental components in the $\alpha \beta$ sub-plane. Therefore, $v_{m}$ can be employed for the voltage feedback in the FW control. As the $v_{m}$ is 5 th and 7 th harmonics-free, it is beneficial for the generation of FW current reference.

The proposed FW control is illustrated in Fig. 3, which is based on VSD for DT-PMSM. By [T6] matrix transformation [41], the phase currents are converted to $i_{\alpha}, i_{\beta}$ in $\alpha \beta$ sub-plane and $i_{z 1}, i_{z 2}$ in $z_{1} z_{2}$ sub-plane. The $i_{d}$ an $i_{q}$ are from conventional Park transformation applied to $i_{\alpha}$ and $i_{\beta}$. The $i_{d z}$ and $i_{q z}$ are from the [ $\left.T_{d q z}\right]$ transformation applied to $i_{z 1}$ and $i_{z 2}$. The fundamental currents are regulated in $d q$-frame in $\alpha \beta$ sub-plane, while the harmonic currents are regulated in $d q z-$ frame in $z_{1} z_{2}$ sub-plane [41]. As there are 5th and 7th harmonic voltages in $z_{1} z_{2}$ sub-plane resulted from the nonsinusoidal back-EMF or inverter non-linearity [41], and then they turn into the 6th harmonics in $d q z$-frame in $z_{1} z_{2}$ subplane, the resonance control with the center frequency of six times of fundament frequency is employed to suppress the 6th harmonic currents in $d q z$-frame in $z_{1} z_{2}$ sub-plane [41].

Besides, the common FW current is forwarded to both phase-ABC and phase-XYZ, where both channels share the same quadrature current reference $i_{q}^{*}$ that comes from either the speed control or torque control, which depends on the application. Therefore, the currents of phase-ABC and -XYZ are naturally balanced in the proposed $\mathrm{FW}$ control based on the VSD control.

\section{EXPERIMENTS}

The test rig to evaluate the conventional $\mathrm{FW}$ control and the proposed FW control for DT-PMSM is constructed based on the TI DSP TMS320F28335 control system shown in Fig. 5. The dual inverter is employed to drive the machine, which has the same power topology as shown in Fig. 1. The execution frequency of the current loop is the same as the PWM frequency of $10 \mathrm{kHz}$. Two independent SVPWM modulators are used for PWM generation for phase-ABC and -XYZ respectively. The prototype DT-PMSM is coupled to another DT-PMSM used for load, which works in torque control mode, while the prototype DT-PMSM works in constant speed control mode. The parameters of the prototype DT-PMSM are shown in TABLE I.

In this Section, four experiments are conducted. The first is the 2-individual current controls without $\mathrm{FW}$ control to demonstrate the phenomenon of the 6th harmonics in the output voltage in $v_{m 1}$ and $v_{m 2}$, and explain why the output voltage magnitude $v_{m}$ is chosen for voltage feedback in the FW control. The second is the conventional FW control based on 2-individual current controls (FW Method-1) with $v_{m 1}$ and $v_{m 2}$ feedback with the main deficiencies of current unbalance and harmonics being presented. Then FW Method-1 is improved by adding a low pass filter (LPF) before the generating FW current reference to suppress the harmonics in Fig. 2, which is named as FW Method-2. The third is the proposed FW with $v_{m}$ feedback based on VSD control to exhibit its superiorities over the conventional FW control based on 2-individual current controls in terms of reduction in current unbalance and harmonics. Finally, the dynamic performance of FW Method-1, FM Method-2, and the proposed FW control with VSD are evaluated.

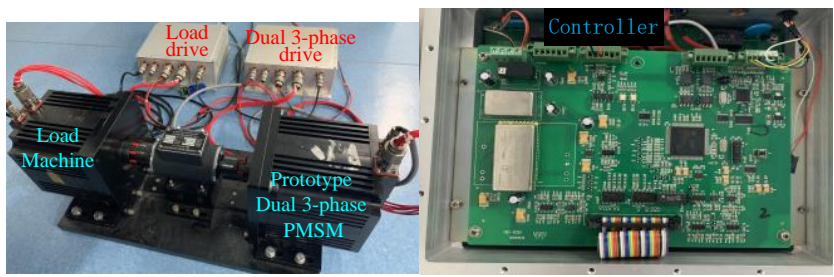

Fig. 5 Test rig for dual three-phase PMSM with phase $\mathrm{Z}$ open.

TABLE I

PARAMETERS OF PROTOTYPE DUAL THREE-PHASE PMSM

\begin{tabular}{ll}
\hline Parameters & Value \\
\hline Resistance $(\Omega)$ & 0.08 \\
Leakage inductance $(\mathrm{mH})$ & 0.864 \\
$d$-axis self-inductance $(\mathrm{mH})$ & 2.82 \\
$q$-axis self-inductance $(\mathrm{mH})$ & 5.00 \\
Flux linkage $(\mathrm{Wb})$ & 0.0785 \\
Pole pairs & 5 \\
Rated Power $(\mathrm{W})$ & 1200 \\
Rated Current $(\mathrm{A})$ & 12 \\
Rated torque $(\mathrm{Nm})$ & 19.1 \\
Rated speed $(\mathrm{rpm})$ & 600 \\
DC link voltage $(\mathrm{V})$ & 80 \\
\hline
\end{tabular}

\section{A) 2-Individual Current Control without FW Control}

In this experiment, the 2-individual current control in Fig. 2 is employed and the drive works in constant speed mode, the $i_{q}^{*}$ is from a speed loop and the speed reference is 600rpm, and the corresponding fundamental frequency is $50 \mathrm{~Hz}$. The DC bus voltage is set deliberately high so that the FW control modules in Fig. 2 are not activated. The $i_{d}^{*}$ reference is set as zero. The loading machine works in constant torque mode and 
the load is increased gradually until the prototype DT-PMSM current is approximately $12 \mathrm{~A}$.

The experimental results are shown in Fig.6. The phase currents are shown in Fig.6(a), where the phase-X current $i_{x}$ lags the phase-A current $i_{a}$ by $30^{\circ}$. The rotor position is inlcuded in the top part of Fig.6(c), (d) and (e). The current profile and corresponding FFT analysis of dq-axis currents are shown in Fig.6(d) and Fig.6(e) respectively, showing that the 6 th harmonics in $i_{d 1}, i_{d 2}, i_{q 1}$, and $i_{q 2}$ are well suppressed by the resonance controller.

The loci of output volage vector $\boldsymbol{v}_{\alpha \beta 1}\left(v_{\alpha 1}+j v_{\beta 1}\right)$ and $\boldsymbol{v}_{\boldsymbol{\alpha} \boldsymbol{\beta} 2}\left(v_{\alpha 2}+j v_{\beta 2}\right)$ for phase-ABC and -XYZ are shown in the left part of Fig.6(b). It is apparent that they are not a circle, which indicates that $v_{\alpha 1}, v_{\beta 1}, v_{\alpha 2}$, and $v_{\beta 2}$ are not sinusoidal. The loci of output voltage vectors in $\alpha \beta$ sub-plane $v_{\alpha \beta}\left(v_{\alpha}+\right.$ $\left.j v_{\beta}\right)$ and $z_{1} z_{2}$ sub-plane $\boldsymbol{v}_{z 1 z 2}\left(v_{z 1}+j v_{z 2}\right)$ are shown in the right part of Fig.6(b). It is closer to a circle than the loci of $\boldsymbol{v}_{\boldsymbol{\alpha} \boldsymbol{\beta} 1}$ and $\boldsymbol{v}_{\boldsymbol{\alpha} \boldsymbol{\beta} 2}$, which means $v_{\alpha}$ and $v_{\beta}$ are much more sinusoidal than $v_{\alpha 1}, v_{\beta 1}, v_{\alpha 2}$, and $v_{\beta 2}$.

The magnitude of vectors $\boldsymbol{v}_{\boldsymbol{\alpha} \boldsymbol{\beta} \mathbf{1}}, \boldsymbol{v}_{\boldsymbol{\alpha} \boldsymbol{\beta} \boldsymbol{2}}$ and $\boldsymbol{v}_{\boldsymbol{\alpha} \boldsymbol{\beta}}$ changing with time and their corresponding FFT harmonic analysis are given in Fig.6(c). From the harmonic analysis, it can be concluded that the major oscillations in $v_{m 1}$ and $v_{m 2}$ are from 6th harmonic voltage, while the 6th harmonic voltage in $v_{m}$ is insignificant. It also indicates that the 6th harmonics in $v_{m 1}$ and $v_{m 2}$ have the same amplitude but in opposite phase; therefore, $v_{m}$ has fewer oscillations than $v_{m 1}$ and $v_{m 2}$. Consequently, if $v_{m}$ is employed as the voltage feedback in the FW control for DT-PMSM, it will be beneficial for the FW current reference without the 6th harmonic current.

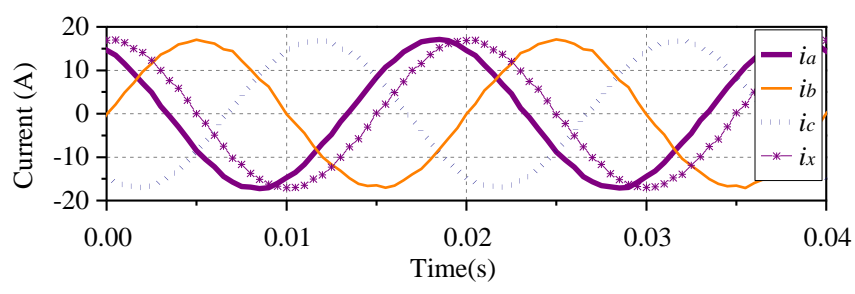

(a) Phase currents
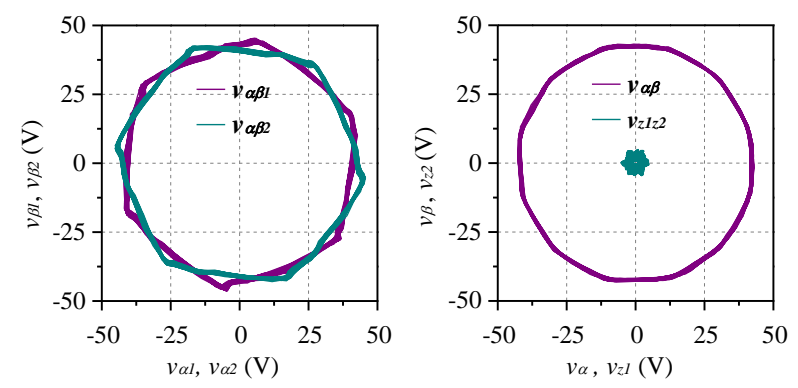

(b) Loci of $v_{\alpha \beta 1}, v_{\alpha \beta 2}, v_{\alpha \beta}$, and $v_{z 1 z 2}$
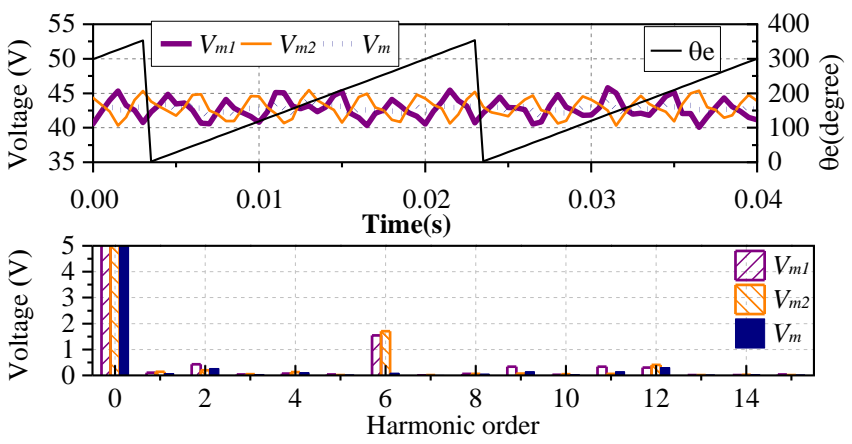

(c) $v_{m 1}, v_{m 2}$ and $v_{m}$
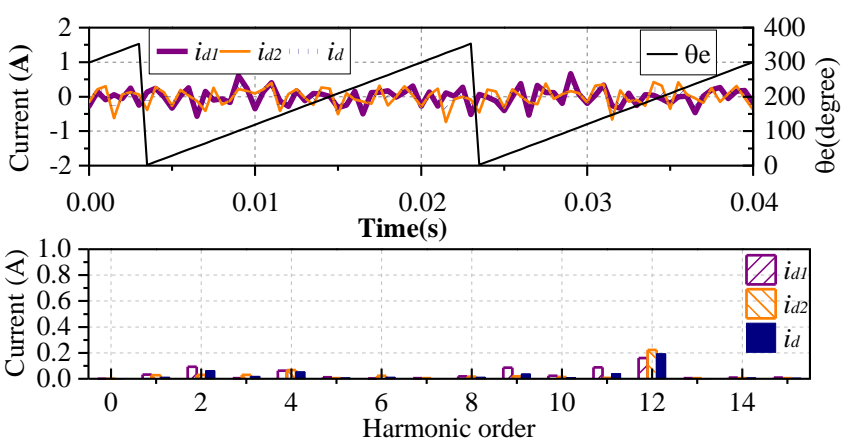

(d) $i_{d 1}, i_{d 2}$ and $i_{d}$
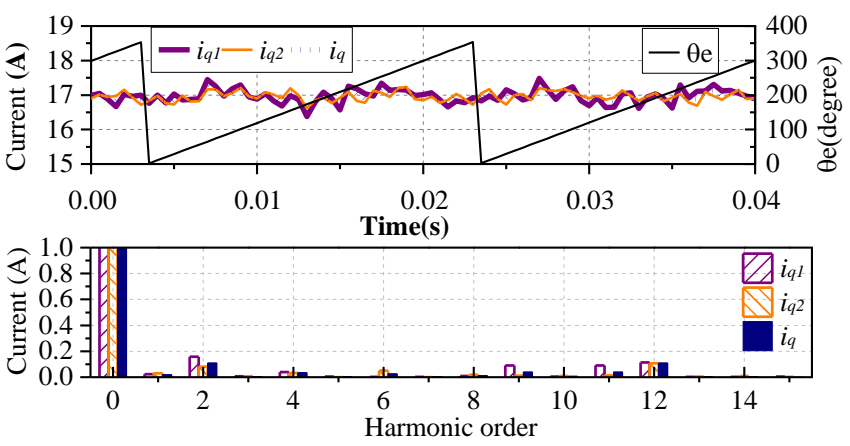

(e) $i_{q 1}, i_{q 2}$ and $i_{q}$

Fig.6 2-individual current control without FW (600rpm constant speed control).

\section{B) 2-Individual Current Control with FW Control}

In this experiment, the FW Method-1, i.e., the 2-individual current control with FW shown in Fig. 2 is employed and the drive also works in constant speed mode. The DC bus voltage is set as $82 \mathrm{~V}$. To trig the FW control, the speed reference is set as 840rpm and the corresponding fundamental frequency is $70 \mathrm{~Hz}$. As the maximum linear output voltage with the SVPWM strategy is $82 \mathrm{~V} / \sqrt{3}=47.3 \mathrm{~V}$, the voltage reference for $\mathrm{FW}$ is set as $42.3 \mathrm{~V}$ for enough voltage margin accounting for the harmonic voltage and inverter non-linearity. The load is increased steadily until the rms current of the prototype machine increases up to 12A. In this case, the FW currents for phase-ABC and -XYZ are not zero and the DT-PMSM works in the FW field.

The phase currents are shown in Fig.7(a), the rotor position is included in the top part of Fig.7(c),(d) and (e), and the loci of output volage vector $\boldsymbol{v}_{\boldsymbol{\alpha} \boldsymbol{\beta} \mathbf{1}}, \boldsymbol{v}_{\boldsymbol{\alpha} \boldsymbol{\beta} \mathbf{2}}, \boldsymbol{v}_{\boldsymbol{\alpha} \boldsymbol{\beta}}$ and $\boldsymbol{v}_{\mathbf{z 1 z 2}}$ are shown in Fig.7(b). The FW currents are shown in Fig.7(d). The results show that the average $\mathrm{FW}$ current for phase-ABC and 
phase-XYZ are different, which means that currents of phase$\mathrm{ABC}$ and phase-XYZ are unbalanced. The FFT analysis of $i_{d 1}$, $i_{d 2}$, and $i_{d}$ shows that there are 2nd harmonic and 6th harmonic currents concurrently in $i_{d 1}$ and $i_{d 2}$. The 2nd harmonic components in Fig.7(d) are slightly higher than those in Fig.6(d), which might be resulted from the asymmetry between phase-ABC and -XYZ. The 6th harmonic currents in $i_{d 1}$, and $i_{d 2}$ are resulted from the 6th harmonic voltages in output voltage feedback $v_{m 1}$ and $v_{m 2}$, as shown in Fig.7(c). There is negligible 6th harmonic in the $i_{d}$ in Fig.7(d), which is because the 6th harmonics in $i_{d 1}$, and $i_{d 2}$ have the same amplitude but in opposite phase. However, it is worth highlighting that those harmonics will result in the deterioration of current THD (total harmonic distortion) and power loss in the system.

In the conventional FW control with two separate channels, the FW current reference comes directly from the FW PI control loop. To suppress the 6th harmonic component in the flux-weakening current, a LPF module can be added after the FW PI controller so that the 6th harmonic in the FW current reference can be suppressed. This method is named as FW Method-2 as mentioned earlier. In this experiment, a LPF with $2 \mathrm{~ms}$ time constant is applied to the FW controller output before the generation of $i_{d 1}^{*}$ and $i_{d 2}^{*}$. The test condition is the same as that for FW Method-1. The experimental results are shown in Fig.8, where the phase currents are shown in Fig.8(a), the loci of $\boldsymbol{v}_{\boldsymbol{\alpha \beta 1}}, \boldsymbol{v}_{\boldsymbol{\alpha} \boldsymbol{\beta} \mathbf{2}}, \boldsymbol{v}_{\boldsymbol{\alpha} \boldsymbol{\beta}}$, and $\boldsymbol{v}_{\mathbf{z 1 z 2}}$ are presented in Fig.8(b), the output voltage feedback $v_{m 1}$ and $v_{m 2}$ are shown in Fig.8(c), while the $d q$-axis currents are shown in Fig.8(d) and Fig.8(e) respectively. The Fig.8 is similar to Fig. 7 with the exception that the 6th harmonics in $i_{d 1}$ and $i_{d 2}$ are trivial. Although implementing a variable bandwidth filter requires more calculation power in the DSP, the experiment results show that it can be an effective way to suppress the 6th harmonics. However, the currents of phase-ABC and $-\mathrm{XYZ}$ are still unbalanced.

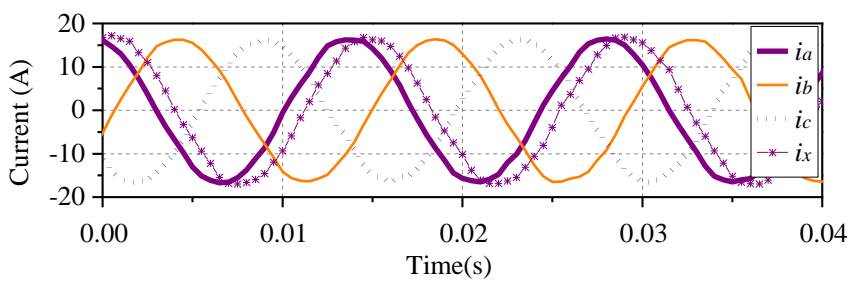

(a) Phase currents
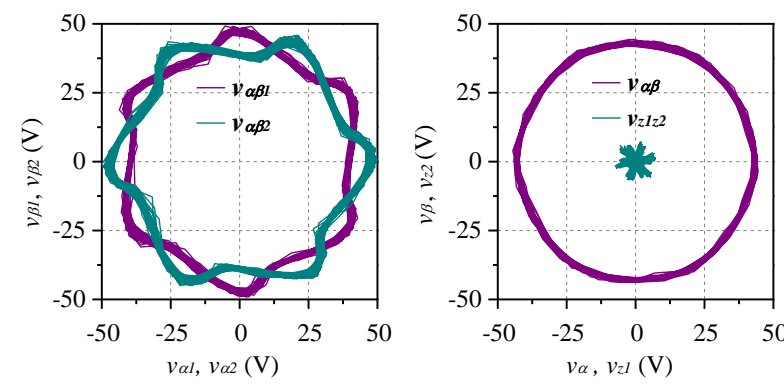

(b) Loci of $v_{\alpha \beta 1}, v_{\alpha \beta 2}, v_{\alpha \beta}$, and $v_{z 1 z 2}$
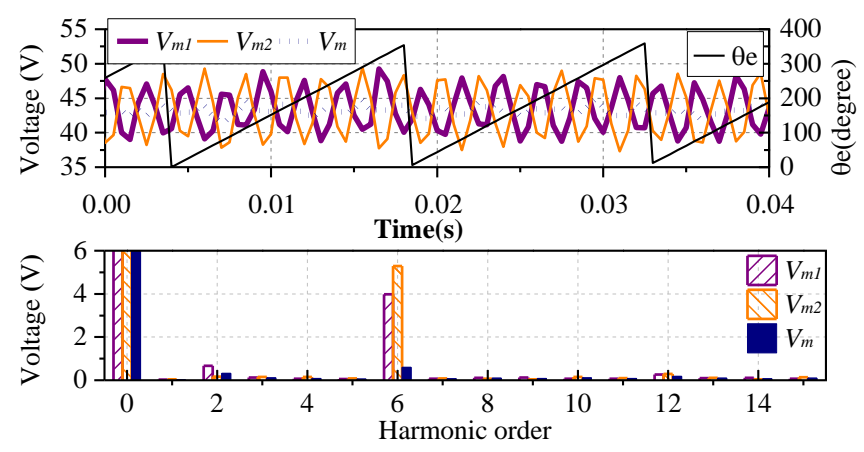

(c) $v_{m 1}, v_{m 2}$ and $v_{m}$
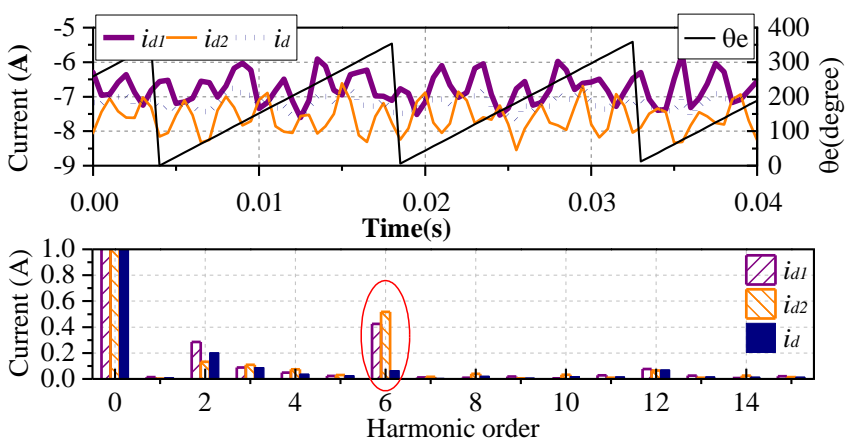

(d) $i_{d 1}, i_{d 2}$ and $i_{d}$
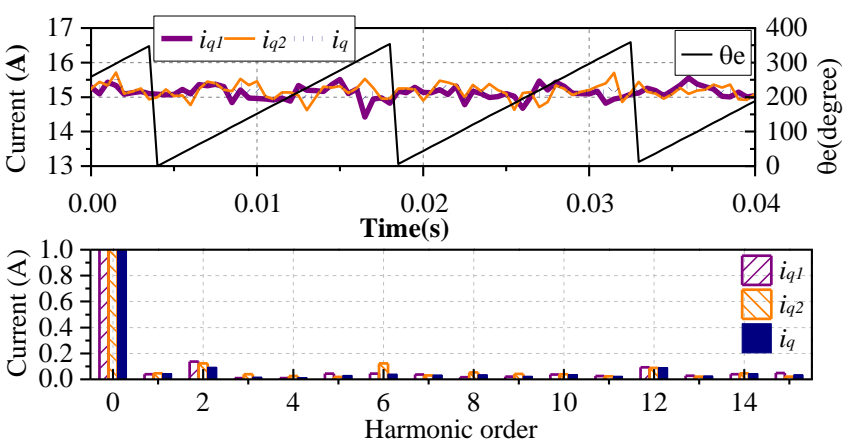

(e) $i_{q 1}, i_{q 2}$ and $i_{q}$

Fig.7 2-individual current control with FW (840rpm, constant speed control).

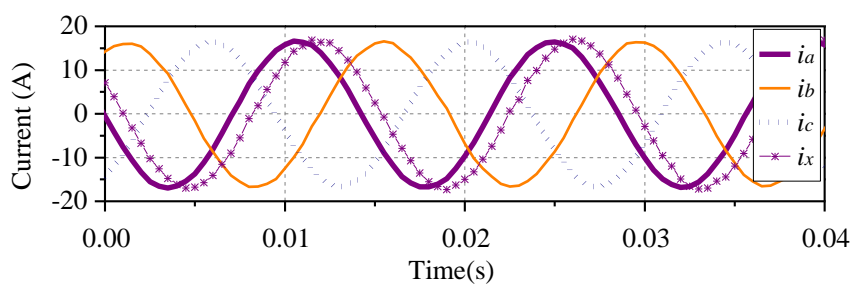

(a) Phase currents
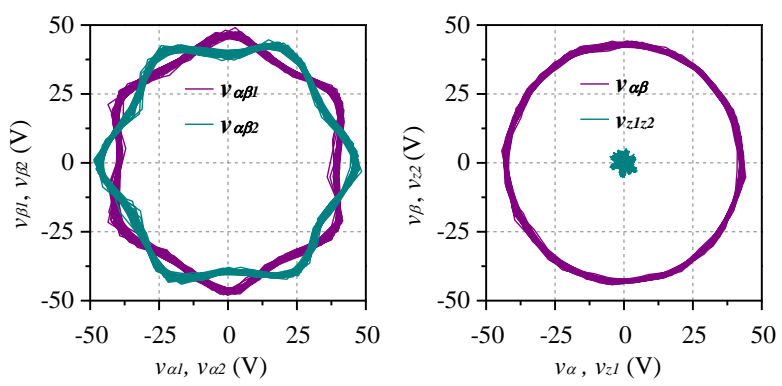

(b) Loci of $v_{\alpha \beta 1}, v_{\alpha \beta 2}, v_{\alpha \beta}$, and $v_{z 1 z 2}$ 

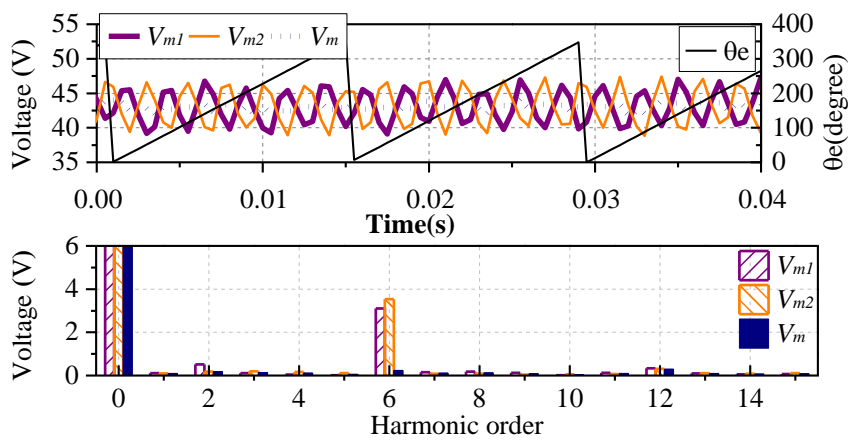

(c) $v_{m 1}, v_{m 2}$ and $v_{m}$

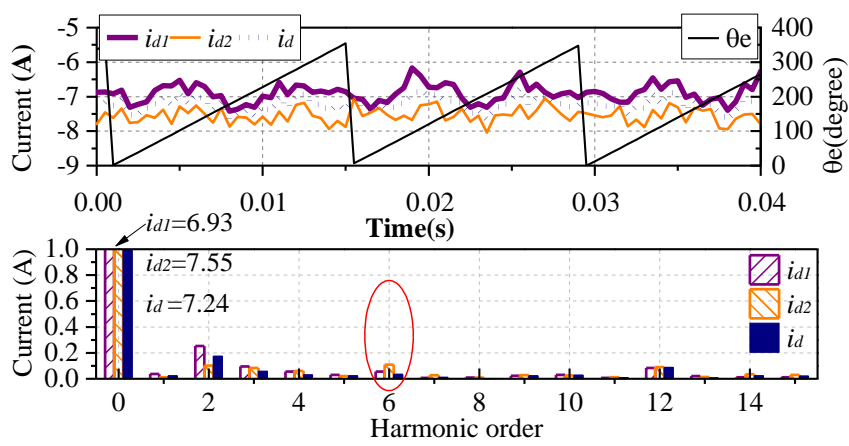

(d) $i_{d 1}, i_{d 2}$ and $i_{d}$
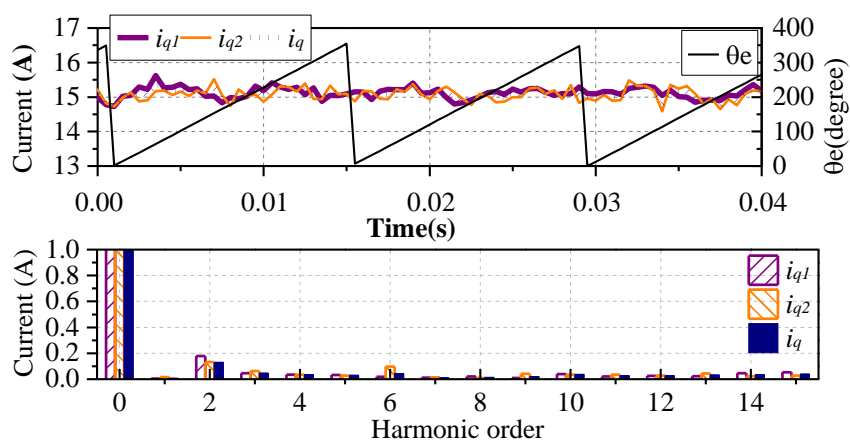

(e) $i_{q 1}, i_{q 2}$ and $i_{q}$

Fig.8 2-individual current control with FW and 2ms LPF for $i_{d}^{*}$ (840rpm, constant speed control).

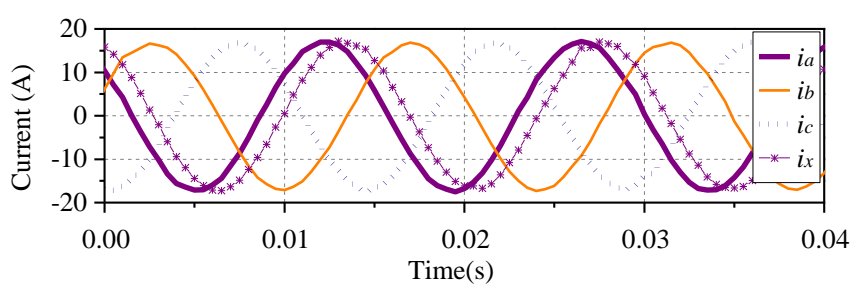

(a) Phase currents
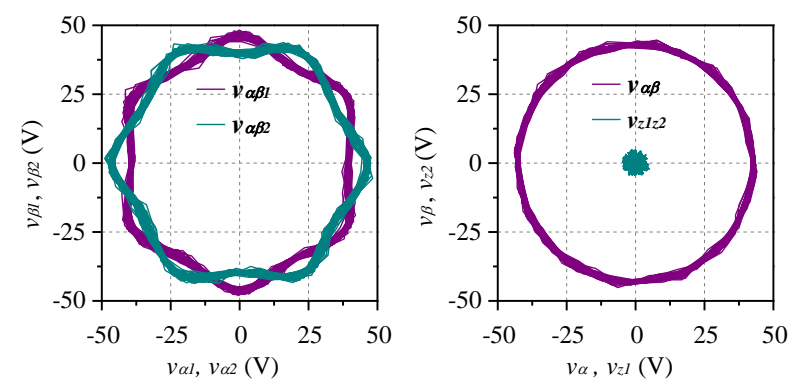

(b) Loci of $v_{\alpha \beta 1}, v_{\alpha \beta 2}, v_{\alpha \beta}$, and $v_{z 1 z 2}$
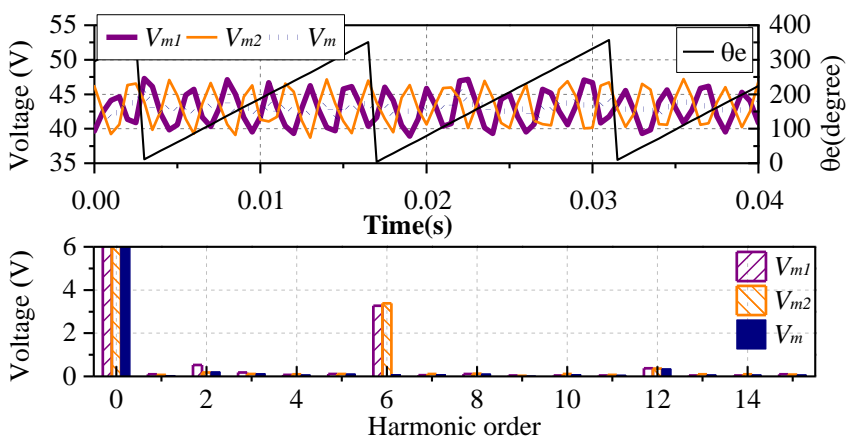

(c) $v_{m 1}, v_{m 2}$ and $v_{m}$
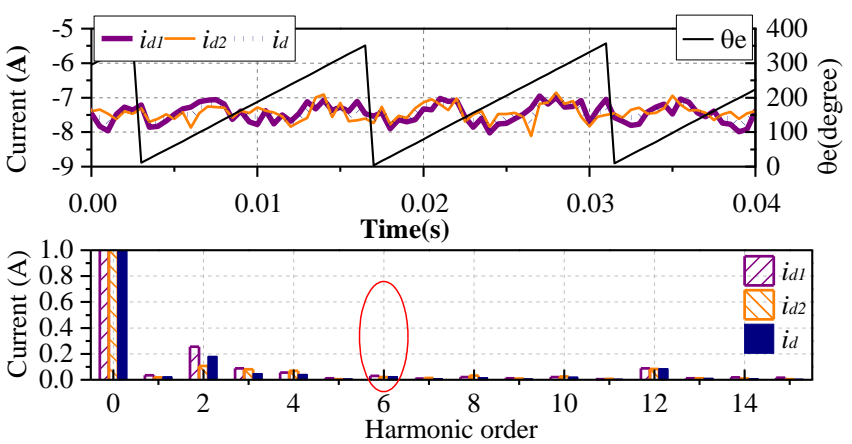

(d) $i_{d 1}, i_{d 2}$ and $i_{d}$
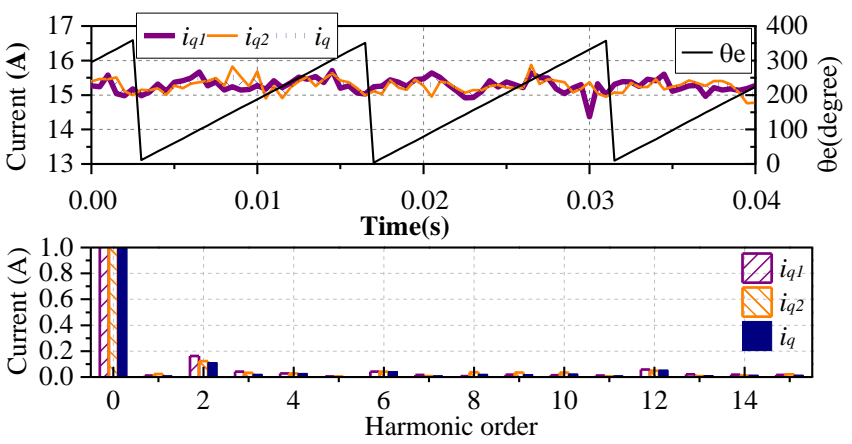

(e) $i_{q 1}, i_{q 2}$ and $i_{q}$

Fig.9 Proposed FW control based on VSD (840rpm, constant speed control).

TABLE II

COMPARISON OF HARMONICS AND UNBALANCE

\begin{tabular}{llll}
\hline Magnitude & FW Method-1 & FW Method-2 & Proposal \\
\hline 6th harmonic in $i_{d 1}(\mathrm{~A})$ & 0.425 & 0.055 & 0.030 \\
6th harmonic in $i_{d 2}(\mathrm{~A})$ & 0.517 & 0.108 & 0.021 \\
Average $i_{d 1}(\mathrm{~A})$ & -6.75 & -6.73 & -7.42 \\
Average $i_{d 2}(\mathrm{~A})$ & -7.57 & -7.53 & -7.42 \\
\hline
\end{tabular}

C) Proposed Flux-Weakening Control Based on VSD Control

In this experiment, the VSD control with FW control shown in Fig. 3 is employed and the prototype DT-PMSM works in constant speed mode. To activate the FW control, the speed reference is set as 840rpm and the corresponding fundamental frequency is $70 \mathrm{~Hz}$. The DC bus voltage is set as $82 \mathrm{~V}$ and the voltage reference for $\mathrm{FW}$ is set as $42.3 \mathrm{~V}$ for enough voltage margin accounting for the harmonic voltage and inverter nonlinearity. The load is also increased steadily until the rms current of drive increases to 12A. In this case, the DT-PMSM works in the FW field. 
The loci of the output voltage vector $\boldsymbol{v}_{\boldsymbol{\alpha} \boldsymbol{\beta} \mathbf{1}}, \boldsymbol{v}_{\boldsymbol{\alpha} \boldsymbol{\beta} \mathbf{2}}, \boldsymbol{v}_{\boldsymbol{\alpha} \boldsymbol{\beta}}$ and $\boldsymbol{v}_{z 1 z 2}$ are shown in Fig.9(b). The magnitude of output voltage feedback $v_{m 1}, v_{m 2}$ and $v_{m}$ are shown in Fig.9(c). The results show that the 6th harmonic voltages are slightly lower than that in Fig.7(c), which may be due to the lower 6th harmonics in $i_{d 1}$ and $i_{d 1}$. Therefore, the reserved voltage margin $v_{\Delta}$ for linear PWM operation accounting for the harmonic voltage and inverter non-linearity could be smaller, and then the output voltage reference $v_{m}^{*}$ and power capability could be higher.

The phase currents are illustrated in Fig.9(a). As can be seen, the phase currents are quite sinusoidal and the phase- $\mathrm{X}$ current $i_{x}$ lags the phase-A current $i_{a}$ by $30^{\circ}$. The rotor position is inlcuded in the top part of Fig.9(c), (d), and (e). The $d$-axis currents and corresponding FFT analysis are given in Fig.9(d). TABLE II gives the harmonic components in $i_{d 1}$ and $i_{d 2}$ and their average value in Fig.7(d), Fig.8(d), and Fig.9(d). Compared with those given in Fig.7(d), there is negligible 6th harmonics in the $i_{d 1}$ and $i_{d 2}$. Meanwhile, the average value of $i_{d 1}$ and $i_{d 2}$ are the same, which is much better than that in Fig.7(d). The $i_{q 1}$ and $i_{q 2}$ are shown in Fig.9(e), which are almost the same as well; therefore, the currents of phase-ABC and phase-XYZ are well balanced,

It is reported that the speed control performance could become worse due to the increased ripple of feedback voltage that is induced by the current reference ripple [48]; meanwhile, higher harmonic currents result in higher power loss and higher THD. Therefore, in terms of the current unbalance and the 6th harmonic current in $i_{d 1}$ and $i_{d 2}$, the proposed FW control in Fig. 3 is superior to the conventional FW control extended for DT-PMSM in Fig. 2.

\section{D) Comparison of Dynamic Performance}

In this experiment, the load is stepped from $44 \%$ to $64 \%$ at the time of $0 \mathrm{~s}$. The step response of FW Method-1, FW Method-2, and the proposed FW control with VSD is shown in Fig.10. The $i_{d 1}$ and $i_{d 2}$ response are illustrated in Fig.10(a) while the output voltages are illustrated in Fig.10(b). When the load is increased by $20 \%$ at $0 \mathrm{~s}$, the speed drops instantaneously, and the output voltage $v_{m 1}$ and $v_{m 2}$ decreases as well, therefore, $v_{m 1}$ and $v_{m 2}$ will be lower than $v_{m}^{*}$. Consequently, flux-weakening current will arise and be limited to zero by a saturation module. As the speed ramps up, due to the constant speed control mode for the prototype DTPMSM, the $v_{m 1}$ and $v_{m 2}$ rises up to $v_{m}^{*}$ and then crosses over with overshoots. As the inputs of the FW current controllers become negative, the $i_{d 1}$ and $i_{d 2}$ decrease so as to lower the $v_{m 1}$ and $v_{m 2}$. This process continues untill $v_{m 1}$ and $v_{m 2}$ agrees with the $v_{m}^{*}$ in steady state. As can be seen from Fig.10, the dynamic performance of all the methods are almost the same, showing an excellent performance. However, it can be observed from Fig.10(a) that average $i_{d 1}$ and $i_{d 2}$ in FW Method-1 and FW Method-2 are not equal in steady-state, which is the major deficiency of FW control based on the 2individual current control.

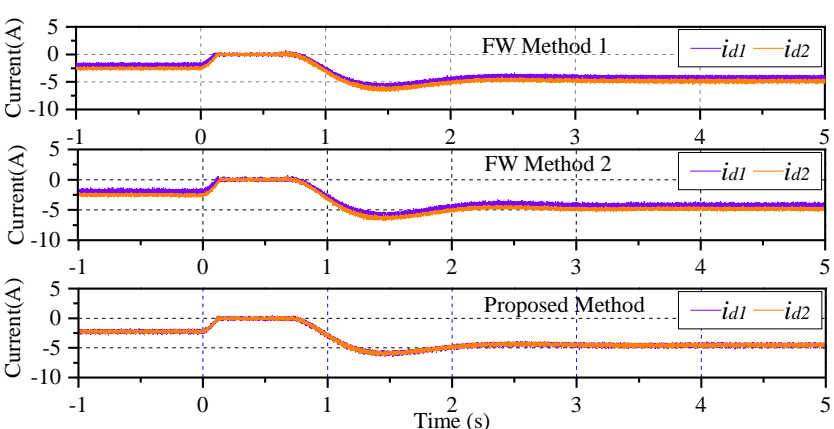

(a) $i_{d 1}$ and $i_{d 2}$

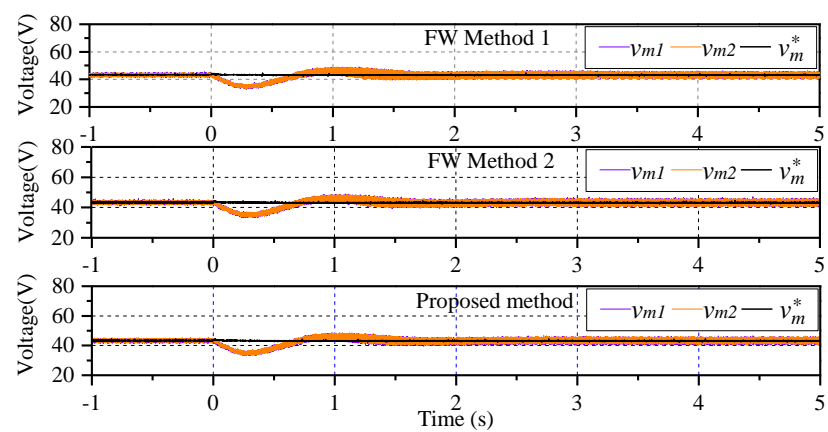

(b) $v_{m 1}, v_{m 2}$ and $v_{m}^{*}$

Fig.10 Step response (FW Method-1: 2-individual current control with FW, FW Method-2: 2-individual current control with FW and 2ms LPF for FW current reference, and the proposed FW control with VSD).

\section{CONCLUSION}

A flux-weakening control of DT-PMSM based on VSD control is proposed and compared with the conventional FW control for each set of single three-phase windings based on the 2-individual current control in this paper. In terms of reduction of the current unbalance and the harmonic current, the proposed approach is superior to the conventional FW control. In the proposed method, the magnitude of voltage in $\alpha \beta$ sub-plane is employed for the voltage feedback. As the 5th and 7 th harmonic voltage resulted from the non-sinusoidal back-EMF and inverter non-linearity are mapped to the $z_{1} z_{2}$ sub-plane according to the VSD theory, the voltage feedback in the FW control is 6th harmonic-free, so as the FW current. Meanwhile, because two sets of three-phase windings share the same FW current and torque current reference, their currents are naturally balanced. On the contrary, the FW currents for each set of three-phase windings in the conventional FW control are unbalanced, and they also have abundant 6th harmonic current if there is no LPF for the FW current reference. It is worth noting that the scenarios in this paper are only investigated in the linear PWM region and the scenarios in the over-modulation region will be studied in the future.

\section{REFERENCES}

[1] L. Parsa, "On advantages of multi-phase machines," in Proc. 31st Annual Conference of IEEE Industrial Electronics Society, 2005, p. 6 pp.

[2] M. A. Abbas, R. Christen, and T. M. Jahns, "Six-phase voltage source inverter driven induction motor," IEEE Trans. Ind. Appl., vol. IA-20, no. 5 , pp. 1251-1259, 1984 . 
[3] Y. F. Zhao and T. A. Lipo, "Space vector PWM control of dual threephase induction machine using vector space decomposition," IEEE Trans. Ind. Appl., vol. 31, no. 5, pp. 1100-1109, 1995

[4] T. M. Jahns, "Improved reliability in solid-state AC drives by means of multiple independent phase drive units," IEEE Trans. Ind. Appl., vol. IA-16, no. 3, pp. 321-331, 1980 .

[5] K. Gopakumar, S. Sathiakumar, S. K. Biswas, and J. Vithayathil, "Modified current source inverter fed induction motor drive with reduced torque pulsations," IEE Proc. B Elect. Power Appl., vol. 131, no. 4, pp. 159-164, 1984

[6] G. K. Singh, K. Nam, and S. K. Lim, "A simple indirect field-oriented control scheme for multiphase induction machine," IEEE Trans. Ind. Electron., vol. 52, no. 4, pp. 1177-1184, 2005.

[7] J. Karttunen, S. Kallio, P. Peltoniemi, P. Silventoinen, and O. Pyrhonen, "Dual three-phase permanent magnet synchronous machine supplied by two independent voltage source inverters," in Proc. Int. Symp. Power Electron., Electr. Drives, Autom. and Motion, 2012, pp. 741-747.

[8] E. Levi, R. Bojoi, F. Profumo, H. A. Toliyat, and S. Williamson, "Multiphase induction motor drives - A technology status review," IET Electr. Power Appl., vol. 1, no. 4, pp. 489-516, 2007.

[9] E. Levi, "Multiphase electric machines for variable-speed applications," IEEE Trans. Ind. Electron., vol. 55, no. 5, pp. 1893-1909, 2008.

[10] L. d. Lillo, L. Empringham, P. W. Wheeler, S. Khwan-On, C. Gerada M. N. Othman, and X. Huang, "Multiphase power converter drive for fault-tolerant machine development in aerospace applications," IEEE Trans. Ind. Electron., vol. 57, no. 2, pp. 575-583, 2010.

[11] W. Cao, B. C. Mecrow, G. J. Atkinson, J. W. Bennett, and D. J. Atkinson, "Overview of electric motor technologies used for more electric aircraft (MEA)," IEEE Trans. Ind. Electron., vol. 59, no. 9, pp. 3523-3531, 2012.

[12] H. Amimeur, D. Aouzellag, R. Abdessemed, and K. Ghedamsi, "Sliding mode control of a dual-stator induction generator for wind energy conversion systems," Int. J. Electr. Power Engery Syst., vol. 42 no. 1 , pp. $60-70,2012$

[13] D. Yazdani, S. Ali Khajehoddin, A. Bakhshai, and G. Joos, "Full utilization of the inverter in split-phase drives by means of a dual threephase space vector classification algorithm," IEEE Trans. Ind. Electron., vol. 56, no. 1, pp. 120-129, 2009.

[14] R. F. Schiferl and T. A. Lipo, "Power capability of salient pole permanent magnet synchronous motors in variable speed drive applications," IEEE Trans. Ind. Appl., vol. 26, no. 1, pp. 115-123, 1990.

[15] W. L. Soong and T. J. E. Miller, "Field-weakening performance of brushless synchronous AC motor drives," IEE Proc. - Elect. Pow. Appl., vol. 141, no. 6, pp. 331-340, 1994.

[16] C. Wang, Z. Q. Zhu, and H. Zhan, "Adaptive voltage feedback controllers on non-salient permanent magnet synchronous machine," IEEE Trans. Ind. Appl., pp. 1-1, 2019.

[17] S. Morimoto, Y. Takeda, T. Hirasa, and K. Taniguchi, "Expansion of operating limits for permanent magnet motor by current vector control considering inverter capacity," IEEE Trans. Ind. Appl., vol. 26, no. 5, pp. $866-871,1990$

[18] B. Cheng and T. R. Tesch, "Torque feedforward control technique for permanent-magnet synchronous motors," IEEE Trans. Ind. Electron. vol. 57, no. 3, pp. 969-974, 2010.

[19] S. Morimoto, M. Sanada, and Y. Takeda, "Effects and compensation of magnetic saturation in flux-weakening controlled permanent magnet synchronous motor drives," IEEE Trans. Ind. Appl., vol. 30, no. 6, p. 1632,1994

[20] R. Dhaouadi and N. Mohan, "Analysis of current-regulated voltagesource inverters for permanent magnet synchronous motor drives in normal and extended speed ranges," IEEE Trans. Energy Convers., vol. 5, no. 1 , pp. $137-144,1990$

[21] M. Tursini, E. Chiricozzi, and R. Petrella, "Feedforward fluxweakening control of surface-mounted permanent-magnet synchronous motors accounting for resistive voltage drop," IEEE Trans. Ind. Electron., vol. 57, no. 1, pp. 440-448, 2010.

[22] H. W. d. Kock, A. J. Rix, and M. J. Kamper, "Optimal torque control of synchronous machines based on finite-element analysis," IEEE Trans. Ind. Electron., vol. 57, no. 1, pp. 413-419, 2010.

[23] S. D. Sudhoff, K. A. Corzine, and H. J. Hegner, "A flux-weakening strategy for current-regulated surface-mounted permanent-magnet machine drives," IEEE Trans. Energy Convers., vol. 10, no. 3, pp. 431437, 1995
[24] K. Jang-Mok and S. Seung-Ki, "Speed control of interior permanent magnet synchronous motor drive for the flux weakening operation," IEEE Trans. Ind. Appl., vol. 33, no. 1, pp. 43-48, 1997.

[25] N. Bianchi, S. Bolognani, and M. Zigliotto, "High-performance PM synchronous motor drive for an electrical scooter," IEEE Trans. Ind. Appl., vol. 37, no. 5, pp. 1348-1355, 2001

[26] L. Harnefors, K. Pietilainen, and L. Gertmar, "Torque-maximizing field-weakening control: design, analysis, and parameter selection," IEEE Trans. Ind. Electron., vol. 48, no. 1, pp. 161-168, 2001.

[27] S. Bolognani, S. Calligaro, and R. Petrella, "Adaptive flux-weakening controller for interior permanent magnet synchronous motor drives," IEEE Journal of Emerging and Selected Topics in Power Electronics, vol. 2, no. 2, pp. 236-248, 2014

[28] N. Bedetti, S. Calligaro, and R. Petrella, "Analytical design and autotuning of adaptive flux-weakening voltage regulation loop in IPMSM drives with accurate torque regulation," IEEE Trans. Ind. Appl., vol. 56, no. 1, pp. 301-313, 2020.

[29] T. Deng, Z. Su, J. Li, P. Tang, X. Chen, and P. Liu, "Advanced angle field weakening control strategy of permanent magnet synchronous motor," IEEE Transactions on Vehicular Technology, vol. 68, no. 4, pp. 3424-3435, 2019.

[30] Z. Dong, Y. Yu, W. Li, B. Wang, and D. Xu, "Flux-weakening control for induction motor in voltage extension region: Torque analysis and dynamic performance improvement," IEEE Trans. Ind. Electron., vol. 65 , no. 5, pp. 3740-3751, 2018.

[31] H. Liu, Z. Q. Zhu, E. Mohamed, Y. Fu, and X. Qi, "Flux-weakening control of nonsalient pole PMSM having large winding inductance, accounting for resistive voltage drop and inverter nonlinearities," IEEE Transactions on Power Electronics, vol. 27, no. 2, pp. 942-952, 2012.

[32] Y. Kwon, S. Kim, and S. Sul, "Voltage feedback current control scheme for improved transient performance of permanent magnet synchronous machine drives," IEEE Trans. Ind. Electron., vol. 59, no. 9, pp. 3373-3382, 2012

[33] B. Stumberger, G. Stumberger, D. Dolinar, A. Hamler, and M. Trlep, "Evaluation of saturation and cross-magnetization effects in interior permanent-magnet synchronous motor," IEEE Trans. Ind. Appl., vol. 39, no. 5, pp. 1264-1271, 2003.

[34] S. Bolognani, L. Peretti, M. Zigliotto, and E. Bertotto, "Commissioning of electromechanical conversion models for high dynamic PMSM drives," IEEE Trans. Ind. Electron., vol. 57, no. 3, pp. 986-993, 2010.

[35] T. Kwon, G. Choi, M. Kwak, and S. Sul, "Novel flux-weakening control of an IPMSM for quasi-six-step operation," IEEE Trans. Ind. Appl., vol. 44, no. 6, pp. 1722-1731, 2008.

[36] B. Bon-Ho, N. Patel, S. Schulz, and S. Seung-Ki, "New field weakening technique for high saliency interior permanent magnet motor," in 38th IAS Annual Meeting on Conference Record of the Industry Applications Conference, 2003., 2003, pp. 898-905 vol.2.

[37] L. Ping-Yi and L. Yen-Shin, "Voltage control technique for the extension of dc-link voltage utilization of finite-speed SPMSM drives," IEEE Trans. Ind. Electron., vol. 59, no. 9, pp. 3392-3402, 2012

[38] Y. Hu, Z. Q. Zhu, and M. Odavic, "Comparison of two-individual current control and vector space decomposition control for dual threephase PMSM," IEEE Trans. Ind. Appl., vol. 53, no. 5, pp. 4483-4492, 2017

[39] R. Bojoi, M. Lazzari, F. Profumo, and A. Tenconi, "Digital fieldoriented control for dual three-phase induction motor drives," IEEE Trans. Ind. Appl., vol. 39, no. 3, pp. 752-760, 2003.

[40] R. Bojoi, F. Profumo, and A. Tenconi, "Digital synchronous frame current regulation for dual three-phase induction motor drives," in Proc. IEEE 34th Annu. Power Electron. Spec. Conf. , 2003, pp. 14751480 vol.3.

[41] Y. Hu, Z. Q. Zhu, and K. Liu, "Current control for dual three-phase permanent magnet synchronous motors accounting for current unbalance and harmonics," IEEE Journal of Emerging and Selected Topics in Power Electronics, vol. 2, no. 2, pp. 272-284, 2014.

[42] J. Karttunen, S. Kallio, P. Peltoniemi, P. Silventoinen, and O. Pyrhonen, "Decoupled vector control scheme for dual three-phase permanent magnet synchronous machines," IEEE Trans. Ind. Electron. vol. 61, no. 5, pp. 2185-2196, 2014

[43] L. Yongjae and H. Jung-Ik, "High efficiency dual inverter drives for a PMSM considering field weakening region," in Proceedings of The 7th International Power Electronics and Motion Control Conference, 2012, pp. 1009-1014 
[44] S. Liu and C. Liu, "Flux weakening control for dual three-phase PMSM," in 2018 Asia-Pacific Magnetic Recording Conference (APMRC), 2018, pp. 1-2.

[45] L. Yan and D. Chengfei, "Flux weakening control technology of multiphase pmsg for aeronautical high voltage dc power supply system," in 2019 22nd International Conference on Electrical Machines and Systems (ICEMS), 2019, pp. 1-5.

[46] S. Bozhko, S. S. Yeoh, F. Gao, and C. Hill, "Aircraft starter-generator system based on permanent-magnet machine fed by active front-end rectifier," in IECON 2014 - 40th Annual Conference of the IEEE Industrial Electronics Society, 2014, pp. 2958-2964.

[47] D. N. Zmood and D. G. Holmes, "Stationary frame current regulation of PWM inverters with zero steady-state error," IEEE Trans. Power Electron., vol. 18, no. 3, pp. 814-822, 2003.

[48] C. Wang and Z. Q. Zhu, "Fuzzy logic speed control of permanent magnet synchronous machine and feedback voltage ripple reduction in flux-weakening operation region," IEEE Trans. Ind. Appl., pp. 1-1, 2020.

[49] F. Mwasilu and J. Jung, "Enhanced fault-tolerant control of interior PMSMs based on an adaptive EKF for EV traction applications," IEEE Transactions on Power Electronics, vol. 31, no. 8, pp. 5746-5758, 2016.

[50] Y. Hu, Z. Q. Zhu, and M. Odavic, "Torque capability enhancement of dual three-phase PMSM drive with fifth and seventh current harmonics injection," IEEE Trans. Ind. Appl., vol. 53, no. 5, pp. 4526-4535, 2017. 
